Int. J. Morphol.,

33(1):393-399, 2015

\title{
La Estatua Anatómica del Dr. Auzoux. Primer Modelo Anatómico de Uso Docente en Chile
}

\author{
The Anatomical Statue of Dr. Auzoux. First Anatomical Model of Teaching Purposes in Chile
}

\author{
Julio Luis Cárdenas Valenzuela*
}

CÁRDENAS, V. J. L. La estatua anatómica del Dr. Auzoux. Primer modelo anatómico de uso docente en Chile. Int. J. Morphol., 33(1):393-399, 2015.

RESUMEN: Llegada a Chile en 1846, la estatua anatómica del Dr. Auzoux fue comprada por el gobierno de la época para el museo de Historia Natural. En 1864, fue donada a la Escuela de Medicina, donde sirve a varias generaciones de estudiantes; es dada por perdida en 1923. Desde entonces fue utilizada despreocupadamente por los estudiantes y docentes, sin saber de su origen, hasta que se inicia su búsqueda, hallándose el año 2005 en regular estado de conservación. Para su restauración, se limpió y eliminó toda sustancia ajena al modelo. Luego, se realizó el registro visual de la "estatua" en conjunto y por separado,desarmándose por regiones para identificar cada una de sus partes, analizándose calidad de conservación del material utilizado, tipo de material, inscripciones y elementos de sujeción utilizadas en su elaboración. Todo el proceso fue respaldado con la toma de imágenes. La estatua correspondió a una figura humana de tamaño natural que representa a un hombre adulto de pie, sin su piel, construido de papel maché (cartón piedra). Su hemicuerpo derecho esta construido en bloque, apoyado desde su pie derecho en un vástago de fierro que termina en una base de tres puntas. Su hemicuerpo izquierdo presenta distintas partes articuladas entre sí por sistemas de ganchos de bronce y ajuste por argollas que permiten encajar sus piezas. Se compone de 26 piezas desmontables que tienen 92 partes en total desarmables y 2000 detalles, cada una identificada con un número En general, las piezas presentan desgaste en las zonas de unión o anclajes, con claro deterioro de su pintura, siendo las zonas más afectadas las que se encuentran expuestas más superficialmente en el modelo. Siendo esta estatua la pieza anatómica documentada más antigua del país y considerando el estado de deterioro de la misma, era imperioso iniciar el proceso de restauración para poder preservarla a las generaciones futuras de anatomistas.

PALABRAS CLAVE: Modelo anatómico; Enseñanza de la Anatomía; Dr. Auzoux; Conservación.

\section{INTRODUCCIÓN}

Según Augusto Orrego Luco, se señala que en 1846 una estatua anatómica habría llegado al país en forma accidental, y que en 1864 ésta habría sido trasladada a la Escuela de Medicina que en esos años se ubicaba en la calle San Francisco, a metros de la Alameda de las Delicias (Laval, 1964)

“(En) El salón de la izquierda estaba en el sitio que ocupaba en el edificio primitivo el gabinete de anatomía del Dr. Lafargue. Una estantería -la misma de los tiempos de Lafargue- cubría todo un costado de la sala. Ahí había una colección de preparaciones y objetos anatómicos, que se guardaban en grandes vocales con alcohol.

Desde 1864 figuraba entre los adornos de esa sala "La estatua anatómica de Ansoux",que el gobierno había comprado en 1.000 pesos.
Esa estatua anatómica era una figura de cartón-piedra, de tamaño natural, cuyas piezas se podían desmontar, dejando ver lo que había dejado debajo del órgano que se había levantado. Esa ingeniosa disposición facilitaba enormemente los estudios anatómicos. Creo que todavía se encuentran en algún rincón olvidado de la Escuela los últimos restos de ese maniquí, en que tantas generaciones iniciaron sus estudios. Entonces tratábamos al maniquí con el cuidado con que se trata todo lo que es nuevo, y después, con el desdén ingrato con que se trata todo lo que es viejo. Prescindiendo de esa estatua y de algún otro detalle, todo se conservaba en esa sala como en los tiempos de Lafargue, que fue el verdadero iniciador de los trabajos anatómicos en Chile" (sic) (Laval).

Quedó en la sala que ocupaba el Dr. Lafargue ubicada a la izquierda de la entrada de la Escuela; en 1922 nos 
hace mención sobre la estatua Anatómica del "Dr. Ansoux” (Orrego, 1922) señalando erróneamente que había llegado en 1864 (posteriormente sabríamos además que ese no era exactamente su apellido lo que dificultó su búsqueda inicialmente). Dándose por perdida desde ese entonces por más de 80 años, pasaron muchas generaciones de alumnos y docentes de Anatomía usando con despreocupación este maniquí, no registrándose ningún comentario conocido sobre esta "estatua" por todo este periodo. Si bien es cierto varias generaciones de alumnos y docentes le habían ocupado activamente para la docencia, no existía registro algunos de su existencia y estado.

Se inició su búsqueda, para lo que se accedió a los archivos de la Biblioteca Nacional (Boletín de las Leyes y de las Órdenes y Decretos del gobierno, 1846) y relatos de anatomistas (Prof. Dr. Walter Ávila el año 2008 y Prof Dr. Alberto Rodríguez Torres el año 2009) y un funcionario antiguo (Sr. Fortunato Gavilán el año 2009), quienes con su valioso testimonio permitieron encontrar, no sin dificultades, pues la primera fuente a la que había accedido, el llamado "Museo de Anatomía", había sido desmantelado por indicación de la autoridad universitaria en el año 2003, con el fín de utilizar dicho espacio para nuevas dependencias de oficinas, desconociendo completamente el patrimonio que ello representaba tanto para la Universidad como para el país.

Es así como en el mes de Junio del año 2005, luego de seguir indicaciones de los funcionarios más antiguos, en el subterráneo del Programa de Morfología se le encuentra junto a receptáculos con fetos de animales y placentas formalinizadas. Allí, de pie, cubierto de polvo y amarrado burdamente permanecía este maniquí desconocido para nosotros (Fig. 1).

Inmediatamente se procede a trasladarla a una sala para iniciar su análisis y descripción, quedando en la sala de disección de los ayudantes, primer piso, en el sector de prosectorías, sector norte. En forma paralela se inicia su búsqueda en Internet por el nombre aparecido en el boletín de las leyes y La revista Médica de 1922, con el nombre de Ansoux, sin embargo esta búsqueda no generaría ninguna información.

\section{Descripción de la pieza}

Es una figura de papel maché con forma humana que representa a un hombre adulto en posición de pie, de más o menos 1,80 metros de altura, sin su piel exponiendo su musculatura, apoyada sobre su miembro inferior derecho en un pedestal de fierro forjado de tres apoyos de suave curvatura.

Su hemicuerpo derecho está construido en bloque, dentro del cual, desde su hombro hasta su pie derecho, está atravesado por un cilindro de fierro que llega hasta la región plantar ipsilateral en la que se encaja un vástago de fierro soldado a una base del mismo material que termina en una base de tres puntas (Fig. 2 ). Su hemicuerpo izquierdo presenta distintas partes articuladas entre sí por sistemas de ganchos de bronce y ajuste por argollas que permiten encajar sus piezas. Se compone de 92 partes y 2000 detalles, cada una identificada con un número. Su miembro inferior izquierdo está levemente flectado y su pie en el aire; su cabeza, ligeramente inclinada hacia abajo y a la derecha En general, las piezas presentan desgaste en las zonas de unión o anclajes, con claro deterioro de su pintura, siendo las zonas más afectadas las que se encuentran expuestas más superficialmente en el modelo.

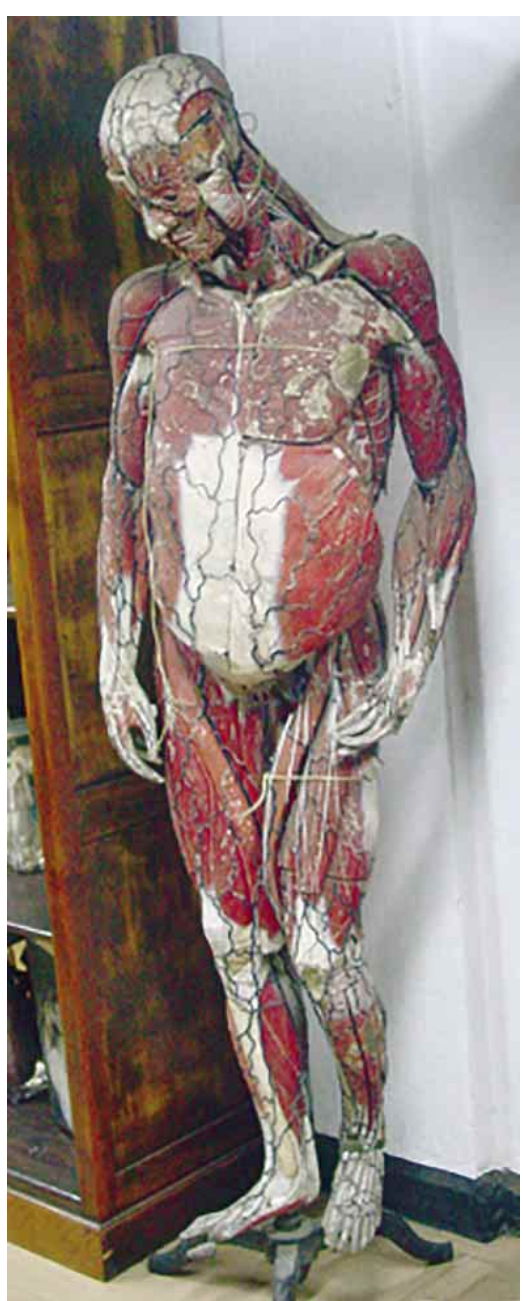

Fig. 1. Estatua Anatómica Dr. Auzoux, año 2005, subterráneo Programa Morfología, Universidad de Chile.

Pintada de rojo su musculatura, destaca un abdomen blanco en su mitad inferior, así como el cráneo, muñecas, rodillas, cara anterior de piernas, región del dorso del pie, por anterior; cara lateral de muslo y región lumbar en una zona de forma trapezoidal. La pintura, claramente deteriorada, está solevantada en toda su extensión y ausente en algunas superficies principalmente en cara anterior de tórax y cara anterior de muslos.

Limpieza y restauración. Se utiliza como guía un manual de preservación de un modelo similar existente en el 


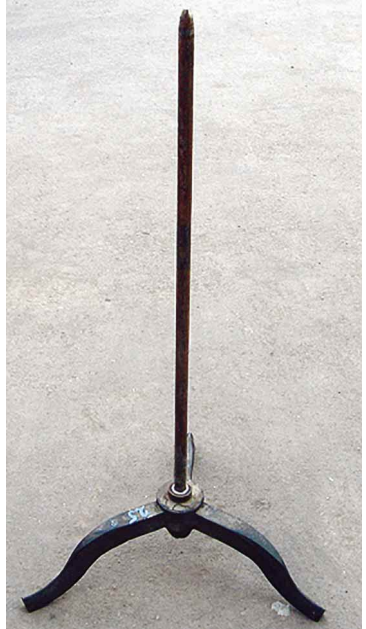

Fig. 2. Base de hierro forjado 3 puntas sobre la cual se apoya la estatua Anatómica Dr. Auzoux.
Instituto Smithsoniano (National Museum of American History, Smithsonian Institution, 1999). Por alrededor de 2 semanas se procede a retirar el polvo superficialmente con una brocha y pincel luego de liberarle de sus amarras. Por cerca de 4 semanas más se van retirando cada una de las piezas, las que se encuentran sujetas con un sistema de ganchos y argollas de bronce a la estructura de papel maché.

Con el fin de reunir mayores antecedentes sobre la pintura solicitamos la concurrencia de académicos de la Escuela de Arte de la Universidad de Chile, quienes analizan la pintura, señalando que estaba pintada al óleo, que se encontraba en mal estado, probablemente porque estuvo sometida a cambios de temperaturas evidentes, así como a la exposición de hongos, por presencia de esporas en su superficie.

Se procede a continuación a desarticular las piezas que constituyen el lado izquierdo de la pieza y posteriormente se limpia cada pieza por separado utilizando primero una suave brocha para retirar el polvo y luego un pincel $n^{\circ} 6$

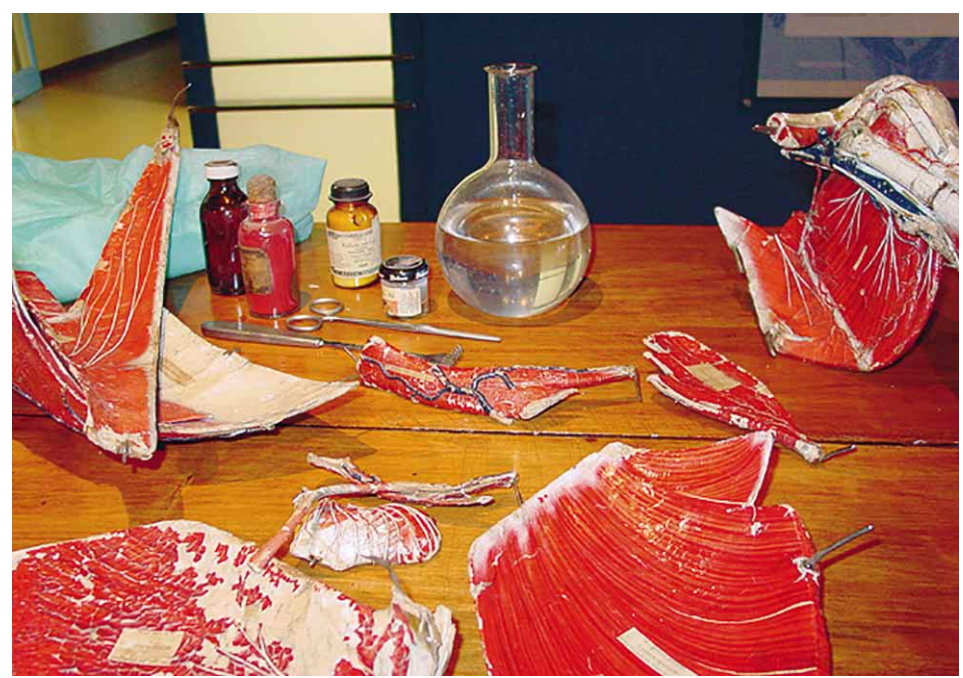

Fig. 3. Limpieza Estatua Anatómica Dr. Auzoux, año 2005, Facultad de Medicina, Universidad de Chile. de pelo de camello, por ser más suave. Posteriormente se inicia la limpieza más profunda de la superficie, con agua destilada y papel japonés absorvente, teniendo el cuidado de no mojar la pieza (Fig. 3). Con ello fue posible recuperar el color original de las partes, permitiéndonos darnos cuenta además que había existido un intento de restauración años atrás de la pintura sobre la pared anterolateral izquierda del abdomen. El error fue haber utilizado en esos años témpera en vez de óleo, la pintura original del modelo. Este proceso duraría alrededor de 4 meses.

Lo anterior permitiría visualizar una inscripción en el muslo derecho que daría la pista sobre la identificación de su autor que señala: Auzoux, Rue 9 L`Ecolé de Medicine, Paris.

Sobre el autor. En virtud del ahora nombre corregido Auzoux, se realizó una búsqueda por Internet (Maerker, 2008; Musée de l'écorché d'anatomie, 2013; Chevalier, 2014; National Museum of American History, Smithsonian Institution, 2014) con lo que se verifica que Louis Thomas Jérôme Auzoux (1797-1880) nació en Saint Aubin d'Escroville cerca de Neubourg, fue un estudiante de Medicina que viendo que eran escasos los cadáveres para disecciones y que los modelos de cera existentes hasta ese momento eran caros, diseña modelos anatómicos hechos de una mezcla de papel maché (papel masticado) con lo que logra abaratar los costos. El primer modelo lo fabrica con apoyo estatal y lo presenta a la Academia Real de Medicina de Francia en 1822. Sus maquetas son un éxito y pronto comienza a realizar maquetas de embriones, plantas y vertebrados.

El primer modelo de hombre en serie lo realiza en 1830. Es así como con la ayuda financiera del estado francés, Auzoux fundó una fábrica para producir modelos anatómicos en su ciudad natal pequeña del d'Ecrosville del St. Aubin en Francia.

Para su realización se utilizaron moldes de plomo. Los vasos sanguíneos se moldearon con alambre pintados de rojo y azul, los músculos se labraban con un cepillo y pintura roja pulverizada. Los nervios, de cáñamo. Las terminaciones eran efectuadas a mano, y se disponía de 2 versiones, una de $1,80 \mathrm{~cm}$ y la otra más barata de $1,30 \mathrm{~cm}$. La dirección de la inscripción en el muslo, corresponde a una tienda de venta de artículos médicos en París.

En contacto con el Musée du Neubourg gentilmente nos envían la página $\mathrm{N}^{\circ} 1$ del catálogo: "L'homme clastique complet", realizado en 
1858 (Fig. 4). Ahí se señala que existe un modelo de 1,80 cms. que tiene 92 partes y más de 2000 detalles con un costo de 3000 francos. Además existía un modelo más pequeño, de $1,16 \mathrm{cms}$. con la misma cantidad de piezas que el anterior, pero con la mitad de sus detalles, con un costo de 1000 francos, y otros 4 modelos como variantes. Luego se detallaban los valores de envío según los modelos.

Como hecho anecdótico de esta búsqueda destaca un célebre relato que menciona que luego de caer la segunda bomba atómica el 9 de Agosto de 1945 sobre la ciudad japonesa de Nagasaki los rescatistas, pensando que se acercaban a restos humanos, asombrados encuentran la mitad derecha de un Auzoux, Viajan restauradores japoneses y alemanes a Neubourg, Francia, para recuperar esta pieza y así luego quedar en exhibición permanente en el Museo de Nagasaki; databa de 1880. Nuestro modelo es de 1846, estaba más completo y lo teníamos olvidado.

- BIUX

GATALOBO영

des snéparatioss

D'ANATOMIE CLASTIQUE (1) DU Dr AUZOUX,

1858.

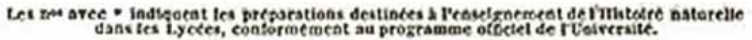

Extratt of propractine ofNitet de renteersite pour int

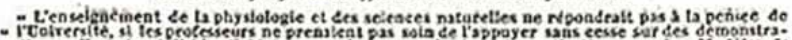

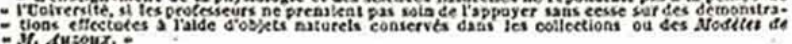

1. - Jomme clastique contplet, de 1 in. 80 ccat, sur tequtel so troureät 92 partics muscles ou orcanes, que l'on peut delaclier, et plus de 2000 objets de détails, ceste-j-dire tout co que pent indiquer le traité le plus $3000 \mathrm{fr}$

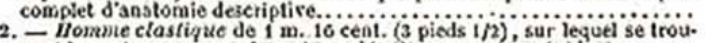

vent les mémes coupes, les meènes détaits que sur le próedeat......... 1000

5. - Momme clastique de 82 cent. ( 2 pieds $1 / 2)$, offrant tous les détails soient ue peu moins multiplies que sur les deux préédents........... 500

s. - Homme clastique de 55 cent. ( 1 pied $1 / 2$ ), aussi complêt que celuil

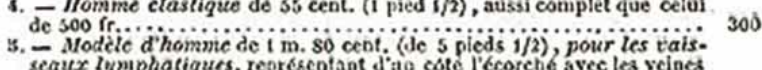
seaux lymphaciguts, representant dat cote lecorche avec les veines tères et veinés, depuis le coeur jusqu'sux plus petites divisions, aveć les ganglions et vaisseaux lymplatiques connus. ............... 300

-c. - Homme clastique incompter. de $1 \mathrm{~m}$. 80 cent. (de 5 pieds $\langle 1 / 2$ ). destinéd Tenseignement de l'nistoirc natarelle dans les Lycees ct les elablissemenls qui ne s'oceupent pas d'une maniere speciale de la pratique de l'art de guerir, representant, d'un cote, les muscles et les

(1) De Ki/kw (Klao), rompre, Brisei, ciest-3.dire Modeles it Auatomio composts de pièces solides, qui peutenl aisément se monter el dêionter, sentever une à une, comme dans tome térilable dissection.

pour se procurer des préparations a Anatomie clastique, it suffil d'adresser the demande à SH. Aisoux, et les fonds, solt par les messageries, soil par un bon sur la joste ou sur un banquier de Paris.

An prix fizé par le calalogue on doil ojouter, poutr temballage, caisse, spafule et supporl, co fr. pour le grand modele, so fr. pour le mogen, et $100 \mathrm{fr}$. pour le cheval. Grand modele dhomme, $n^{\circ}$ t................ $100 \mathrm{fr}$

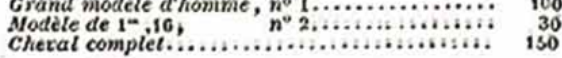

Fig. 4. Portada catálogo de preparaciones clásticas del Dr. Auzoux, año 1858. Gentileza Musée du Neubourg, Francia.
Otro hecho fortuito que contribuiría al estudio histórico de esta pieza fue la presentación por parte del encargado del Museo de Historia de la Medicina de la Facultad de Medicina de la Universidad de Chile en el año 2007 de una estampa en la que aparecía un modelo anatómico al lado de una persona (Fig. 5), estampa que pertenecia al Dr. Vicente Izquierdo y traída por él desde Europa en la primera mitad del siglo XX y donada posteriormente por su familia, la que tenía sólo algunas letras de un nombre: "Dr. A z ux". Grande sería su sorpresa al mostrármela y escuchar todos estos antecedentes recopilados, pues llevaba meses tratando de averiguar su origen.

Registro de imágenes. Se registra el estado de todas y cada una de las piezas que componen el modelo, asignándole un nivel de restauración según el caso. Para ello se utiliza una cámara digital Sony 4,1 Megapixeles, Cyber shoot, DSC-S85, de resolución 1600. Las imágenes se analizan en un compu-

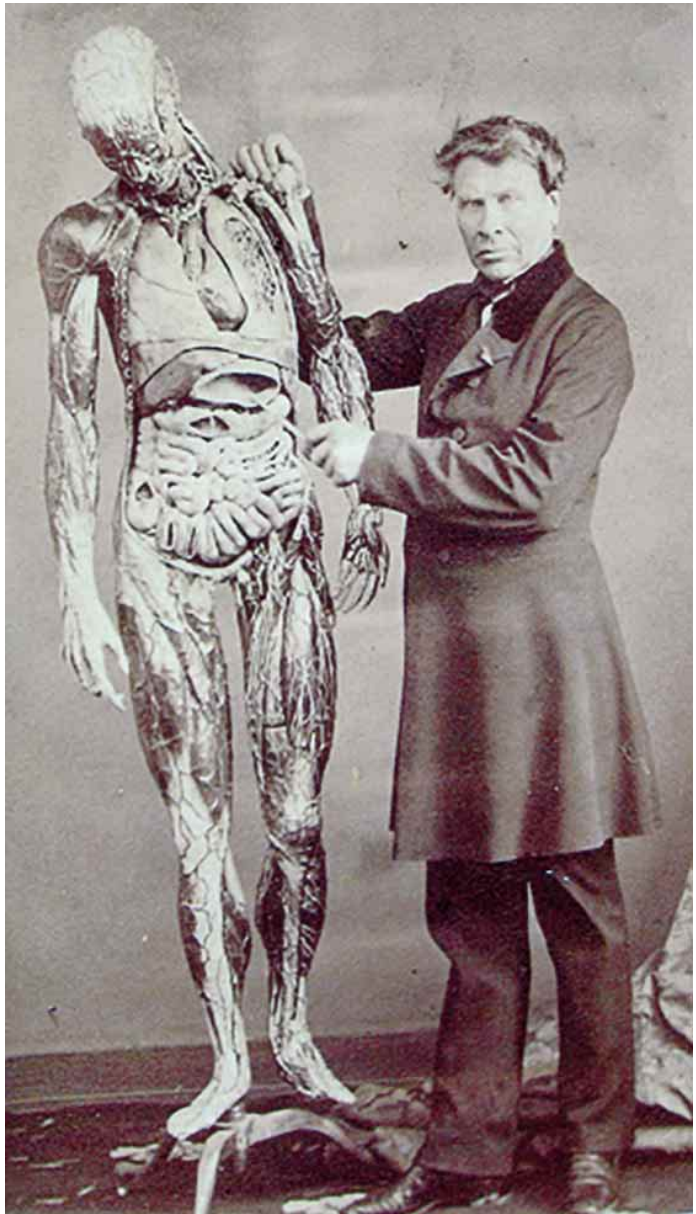

Fig. 5. Estatua Anatómica Dr. Auzoux. Fotografía perteneciente al Dr. Vicente Izquierdo, donada por su familia al Museo de Historia de la Medicina,año 2009 Facultad de Medicina U. de Chile. Gentileza Museo de Historia de la Medicina. 
tador Macintosh G4, utilizando un programa Pixela, guardando las imágenes en formato JPG, para posteriormente editar un CD utilizando los programas Power Point y ROXIO para su grabación.

Luego se utilizan distintos equipos de Radiología SIEMENS, diversos modelos, y un Scanner SIEMENS Somatron Sensation de 64 canales, con el programa syngo CT 2006 A-W para análisis de las imágenes digitales, realizando la reconstrucción tridimensional del modelo, tanto de su superficie, cómo de sus elementos de armazón internos.

Descripción interna. Del análisis radiológico con rayos $\mathrm{X}$ al modelo, realizado en el Servicio de Imagenología del Hospital Clínico de la Universidad de Chile, se concluye que existe un armazón interno con vástagos que dan la armazón a los miembros, el principal siguiendo el eje y otros accesorios dando firmeza a los miembros. Cada pieza está dispuesta de esta manera, con un vástago central y varios alambres unidos a él que le dan el volumen.

Desde la base del pie derecho asciende un vástago que llega hasta la región cervical y que le da su sujeción al modelo desde su pedestal, permitiéndole además girar el modelo en $360^{\circ}$. La disposición espacial de la armazón permite verificar el daño que el modelo tiene en el papel maché producto de dicha arquitectura.

Descripción de las piezas articuladas. Una vez expuestas las piezas por separado es posible evidenciar que cada una de ellas tiene asignado un número de color negro dispuesto sobre un papel café claro de 3 a $12 \mathrm{~mm}$ de ancho y 12 a $70 \mathrm{~mm}$ de longitud, y otro papel del mismo color que señala el nom- bre del órgano, su función, y en caso de los músculos, su inserción proximal y su inserción distal, todo en idioma francés. Estos se encuentran adheridos a la superficie de las piezas, por lo que requirió de gran cuidado para no desprenderlos. Además existen otros círculos de papel de más o menos 4 mm de diámetro sobre músculos y vasos sanguíneos con letras en su superficie, especialmente en región de cara y cuello.

En cuanto a los músculos representados el medio de sujeción entre las distintas piezas corresponde a un sistema de argollas y ganchos de bronce de más o menos $10 \mathrm{~mm}$ de diámetro las argollas en un extremo de la pieza y un gancho de más o menos $34 \mathrm{~mm}$ (variable según la pieza a considerar), con un vástago en el otro extremo que se introduce en una depresión u orificio en el otro órgano, siendo necesario primero desenganchar este dispositivo antes de sacar la pieza y efectuar el movimiento contrario, esto es primero colocar el vástago para luego sujetarle con el gancho si se desea colocar en su lugar nuevamente. Es posible evidenciar que en algunas piezas, el lugar dónde existía la argolla no existe, o bien el orificio del vástago es más grande del tamaño original, lo que hace que ciertas piezas queden sueltas.

En relación a los órganos internos, éstos tienen un sistema de sujeción similar, en los que además, en los órganos huecos existe una cara que se desarticula mostrando en le interior la disposición de sus mucosas. En los órganos macizos cómo el pulmón y el hígado éstos presentan una sección que se desarticula mostrando el parénquima del órgano. Los órganos ausentes son el cerebro y el corazón, este último reemplazado por un corazón de cera de color burdeo, dispuesto en su lugar sin relación con las estructuras vecinas. También están ausentes los genitales masculinos externos.

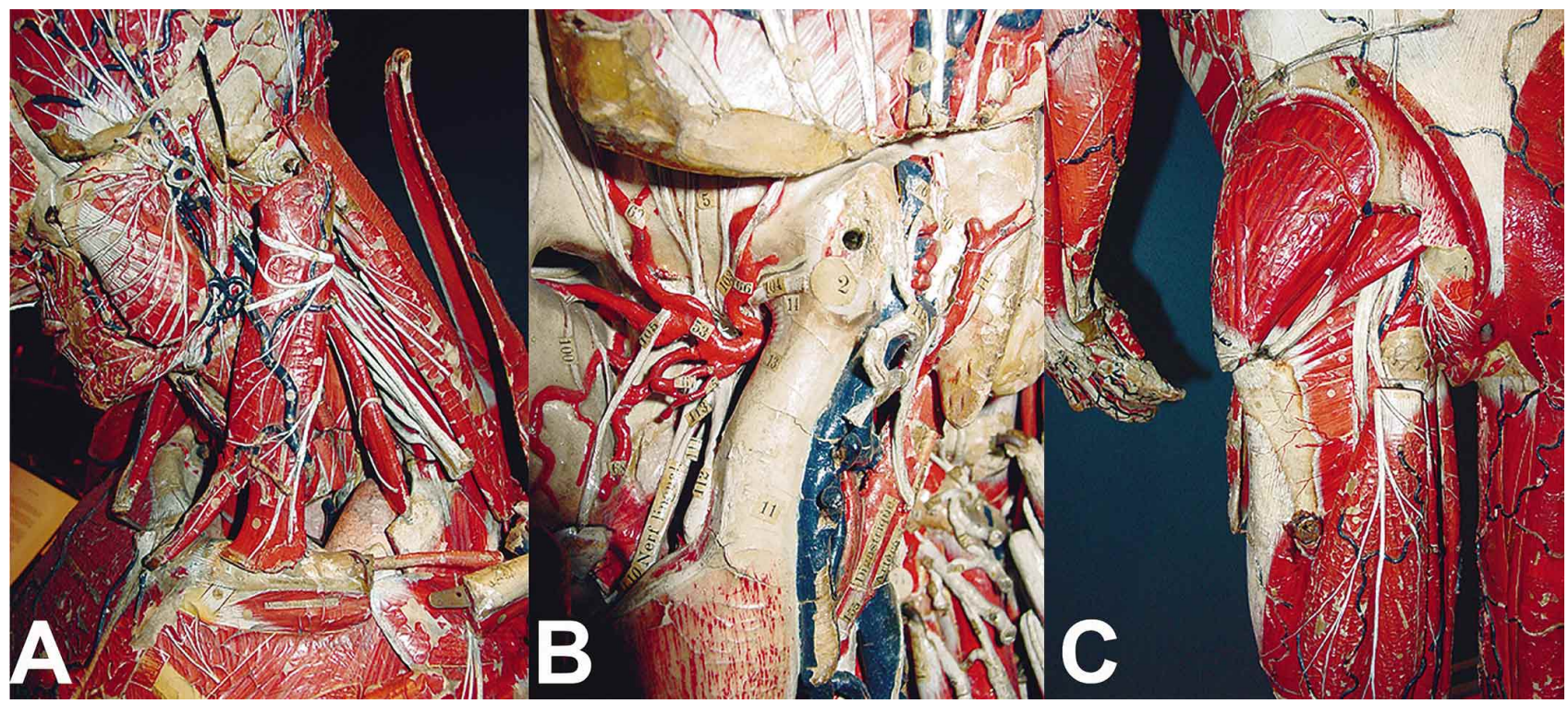

Fig. 6. Armado del modelo. A. Visión lateral izquierda región cervical; B. Distribución ramas arteria maxilar izquierda; C. Región glútea. 
Armado del Modelo. Una vez analizado este modelo, se procede a su rearmado (Fig. 6) y se dispone su ubicación en un sitio destacado dentro del futuro Museo de Anatomía de la Escuela de Medicina de la Universidad de Chile (Fig. 7), en el $2^{\circ}$ Piso del Instituto de Anatomía, en parte de las antiguas dependencias, junto a otras piezas recopiladas hasta hoy.

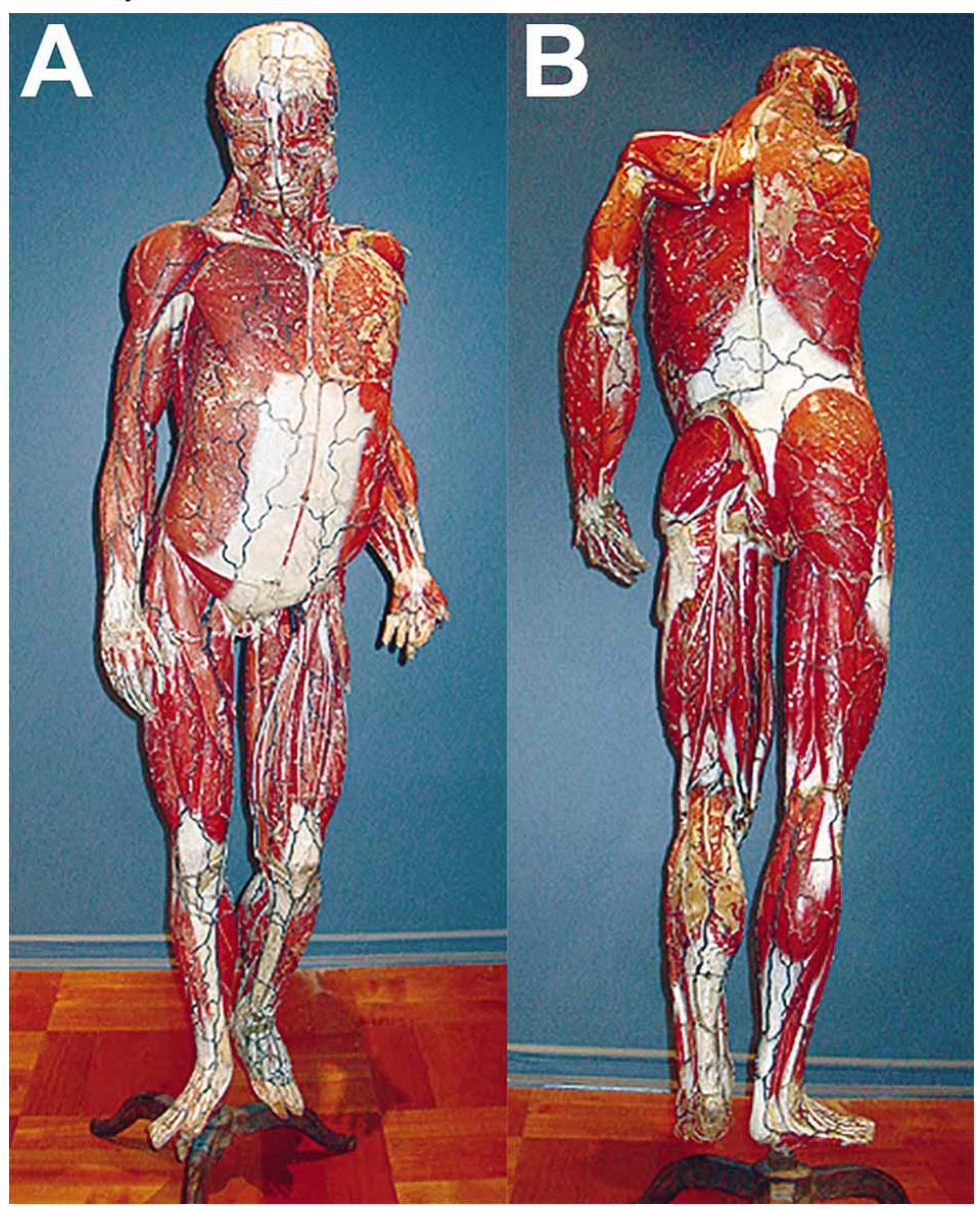

Fig. 7. Estatua anatómica del Dr. Auzoux restaurada año 2008. Museo Anatomía, Facultad de Medicina, Universidad de Chile. A. Visión anterior. B. Visión posterior sin miembro superior derecho.

\section{DISCUSIÓN}

No sólo fue posible establecer el orígen y compra de esta pieza llegada a Chile en 1846, sino también identificar a su autor y forma de elaboración, diseñándose un plan de limpieza y restauración adecuados que concluyeron en el análisis y descripción tanto externo como interno de la pieza con el análisis de imágenes tomográficas. antes expuesto.

De esta manera es posible resguardar de mejor forma este modelo, pues producto de esta investigación sobre la búsqueda del modelo anatómico del Dr. Auzoux, se le pudo dar la importancia dentro del contexto nacional que esta pieza tiene en la docencia de la anatomía en
Chile, posicionándola como la pieza anatómica más antigua de docencia, pudiendo en un futuro cercano restaurarla y conservarla en un lugar apropiado para ello, permitiendo su resguardo para las próximas generaciones tanto de estudiantes del área de la Salud como del público en general de nuestro país. El modelo anatómico sigue siendo utilizado activamente en la docencia anatómi$\mathrm{ca}$, incluso en apoyo de muestras itinerantes como Bodies The Exhibition, Marzo 2008, Santiago Chile y sería tomado como modelo para realizar una réplica en miniatura por la Sociedad Chilena de Anatomía como manera de reconocimiento a sus anatomistas destacados, tal como sucedió en ceremonia efectuada en la ciudad de Talca, Chile, el día 20 de Noviembre de 2013.

CÁRDENAS, V. J. L. The anatomical statue of Dr. Auzoux. First anatomical model of teaching purposes in Chile. Int. J. Morphol., 33(1):393-399, 2015.

SUMMARY: Arrival in Chile in 1846, the anatomical statue of Dr. Auzoux is purchased by the government for the Museum of Natural History. In 1864, it was donated to the School of Medicine, serving several generations of students, and given up for lost in 1923. Since then was casually used by students and teachers, unaware of their origin, until it begins its search, being in 2005, in a regular condition. For restoration, it was cleaned every substance outside the model. Then, we carried out a visual record of the "statue" jointly and separately, disarming by regions to identify each of its parts, analyzing the conservation quality of the material used, type of material, inscriptions and fasteners used in its preparation. The whole process was supported by digital images. The statue corresponded to a life-size human figure representing an adult man standing without his skin, constructed of papier mache. The right hemisphere is built block, leaning from his right foot on a iron rod ending in a three-point basis. The left side of the body has different hinged together by systems bronze hooks and eyelets that allow adjustment parts fit parts. It consists of 26 removable parts with 92 parts total separable and 2000 details, each identified by a number. In general, the parts for wear in the joint areas or anchors, with clear deterioration of his painting, being more exposed surface areas in the model the most affected. Since this statue is the oldest documented anatomical object of the country and considering the state of disrepair of it, it was imperative to start the restoration process to preserve it for future generations of anatomists.

KEYWORDS: Anatomical Model; Teaching Anatomy; Dr. Auzoux; Conservation. 


\section{REFERENCIAS BIBLIOGRÁFICAS}

Boletín de las Leyes y de las Órdenes y Decretos del gobierno. Valparaíso, Imprenta del Mercurio, 1846. pp.357-8.

Chevalier, M. N. Musée d'anatomie. 2014. Available in: http:// www.leneubourg.fr/vivre/7-culture_et_loisirs/2883-musees/ 2808-musee_d_anatomie/

Laval, E. Evolución de la enseñanza de la anatomía en Chile. An. Chil. Hist. Med., 6(2):7-75, 1964.

Maerker, A. 'Dr. Auzoux's papier-mâché models'. Explore Whipple Collections. Whipple Museum of the History of Science. Cambridge, University of Cambridge, 2008. Available in: http:/ /www.hps.cam.ac.uk/whipple/explore/models/ drauzouxsmodels/

Musée de l'écorché d'anatomie. Le Neubourg, France. 2013. Available in: http://www.musee-anatomie.fr/

National Museum of American History, Smithsonian Institution. Conservation Treatment: Anatomical Model of a Man. In: Artificial anatomy: Papier-mâché models. 1999. Available in: http://americanhistory.si.edu/anatomy/preservation/ conservation_report_1.pdf

National Museum of American History, Smithsonian Institution. History; Before Papier-Mâché, In: Artificial anatomy: Papiermâché models. 2014. Available in: http:// a mericanhistory.si.edu/anatomy/history/ nma03_history_before1.html

Orrego, L. A. Recuerdos de la Escuela. Rev. Med. Chile, 50:16191, 1922

\section{Dirección para Correspondencia: Julio Luis Cárdenas Valenzuela \\ Profesor Asistente}

Académico Programa Anatomía y Biología del Desarrollo

Director Museo Anatomía

Facultad de Medicina

Universidad de Chile

Santiago

CHILE

Email: jcardena@med.uchile.cl

Recibido: 31-03-2014

Aceptado: 22-11-2014 